\title{
CAPILLARY ACTIVE INTERIOR INSULATION SYSTEMS FOR WALL RETROFITTING: A MORE NUANCED STORY
}

\author{
EVy VEREECKEN ${ }^{1}$ AND StAF ROELS ${ }^{2}$
}

${ }^{1} \mathrm{KU}$ Leuven, Building Physics Section, Kasteelpark Arenberg 40, B-3001 Leuven, Belgium, +32 16321098

Evy.Vereecken@bwk.kuleuven.be

2 KU Leuven, Building Physics Section, Kasteelpark Arenberg 40, B-3001 Leuven, Belgium

Staf.Roels@bwk.kuleuven.be

\section{Abstract}

To thermally upgrade exterior masonry walls, interior insulation is often the only possible retrofitting technique, especially when dealing with historic buildings. Unfortunately, it is also the most risky post-insulation technique, as frost damage, interstitial condensation and other damage patterns might be induced. To diminish those risks, nowadays so-called capillary active interior insulation systems are often promoted. These systems aim a minimal reduction of the inward drying potential, while interstitial condensation is buffered.

Currently, several capillary active systems are on sale. These different types have, however, widely varying properties. In this paper, a closer look at the hygrothermal 
Postprint: Vereecken E, Roels S. 2016. Capillary active interior insulation systems for wall retrofitting: A more nuanced story. Accepted for publication in International Journal of Architectural Heritage: Conservation, Analysis, and Restoration 10(5), p. 558-569, DOI: 10.1080/15583058.2015.1009575.

properties and the working principle of a number of 'capillary active' interior insulation systems is made. The spread in capillary absorption coefficients and the vapour diffusion resistances of the different systems is discussed and their influence is illustrated. Based on all this, a more nuanced view on capillary active insulation systems is pursued.

\section{KEY WORDS:}

Capillary active interior insulation, hygrothermal performance, wall retrofitting, diffusion resistance, capillary absorption coefficient, moisture drying

\section{SYMBOLS}

$\begin{array}{ll}\text { AC } & \text { aerated concrete } \\ \text { CaSi } & \text { calcium silicate } \\ \text { GM } & \text { glue mortar } \\ \text { GB } & \text { gypsum board } \\ \text { HAMFEM } & \text { Heat Air and Moisture Finite Element Method } \\ \text { MW } & \text { mineral wool } \\ \text { PE } & \text { polyethylene } \\ \text { PIR } & \text { polyisocyanurate } \\ \text { PUR } & \text { polyurethane }\end{array}$


Postprint: Vereecken E, Roels S. 2016. Capillary active interior insulation systems for wall retrofitting: A more nuanced story. Accepted for publication in International Journal of Architectural Heritage: Conservation, Analysis, and Restoration 10(5), p. 558-569, DOI: 10.1080/15583058.2015.1009575.

VIP vacuum insulation panel

WFB wood fibre board

XPS extruded polystyrene

sddry dry vapour diffusion resistance factor

Hdry $\quad$ dry vapour diffusion resistance

\section{INTRODUCTION}

For ages, energy efficiency was no high priority criterion when dealing with historical buildings. Recently, however, political, social and economic motives in combination with an increasing adaptive reuse of historical buildings (Bullen, 2007; Rabun and Kelso, 2009; Wand and Zeng, 2010; Philokyprou, 2014) forced a thought-through energy use in these buildings as well (Geva, 1998). The energy efficiency of buildings depends on the thermal performance of the building envelope, the HVACsystem and the user behaviour. From these, a thermal improvement of the building envelope should be considered as the first and most important retrofitting step. However, due to regulations, the preference to conserve the historical view and other concerns, this can be quite challenging when dealing with historical buildings (Pauliny and Varga, 2014). For instance, in respect to the building walls, which are for historical buildings mostly single leaf walls, interior insulation often remains the only solution to thermally upgrade the historical facades (Häupl et al., 2003; Grunewald et al., 2006). When applying interior insulation, due caution is, however, 
Postprint: Vereecken E, Roels S. 2016. Capillary active interior insulation systems for wall retrofitting: A more nuanced story. Accepted for publication in International Journal of Architectural Heritage: Conservation, Analysis, and Restoration 10(5), p. 558-569, DOI: 10.1080/15583058.2015.1009575.

required, as interior insulation can significantly modify the hygrothermal performance of the wall (Maurenbrecher, 1998), which might induce frost damage (Maurenbrecher, 1998), interstitial condensation (Vereecken and Roels, 2014a), mould growth and other damage patterns (Straube and Schumacher, 2007).

To reduce the risk on these damage patterns, and thus to support the preservation of our cultural heritage, nowadays often so-called capillary active interior insulation systems are promoted (Grunewald et al., 2006; Remmers, 2014; EP 1900884 A1, 2008). According to the literature, such systems are vapour open systems that avoid interstitial condensation due to the capillary forces of the insulation material, while a drying out is still possible. A reverse formulation is, however, more logical; capillary active systems aim to diminish the reduction of the drying rate of the original wall by allowing an inward drying, while interstitial condensation is buffered. Additionally, it is often claimed that those systems regulate the indoor climate, which would make them even more interesting to apply in historical buildings, especially if these buildings are used as museums or if they still have their authentic furniture. The idea of a capillary active and hygroscopic system that regulates the indoor climate is, however, largely disproved in a previous study (Vereecken and Roels, 2014b) that shows the interior finishing layer as the decisive factor for buffering the peaks in relative humidity. As a matter of fact, auxiliary dehumidification can, even if appropriate finishing materials are present, not be excluded, as concluded in (Padfield et al., 2007). And although the moisture distribution in a masonry wall retrofitted with a capillary active interior insulation system leans - compared to this found for a vapour tight interior insulation system - more toward this of a non- 
Postprint: Vereecken E, Roels S. 2016. Capillary active interior insulation systems for wall retrofitting: A more nuanced story. Accepted for publication in International Journal of Architectural Heritage: Conservation, Analysis, and Restoration 10(5), p. 558-569, DOI: 10.1080/15583058.2015.1009575.

insulated wall, the inward moisture redistributions that causes this effect might induce some drawbacks as well (Vereecken and Roels, 2014b). In this respect, a probabilistic study (Vereecken et al., 2015) concluded that capillary active systems might be beneficial when wooden beam ends are present or when frost damage should be avoided, though a higher surface relative humidity could be induced and a lower thermal improvement is achieved. The thermal resistance of the insulation system can even be worsened if a vapour tight painting coat is added (Vereecken and Roels, 2014b). Provision of a rain shelter could avoid some moisture related damage patterns, though, nullifies the motivation of applying a capillary active insulation system to allow an inward drying of the absorbed wind-driven rain. Moreover, for a wall not exposed to rain, there is no reason to choose for a capillary active system, as its thermal performance is less while the hygrothermal risks are similar to those found for a vapour tight system (Vereecken et al., 2015).

Most of the current studies are, however, performed for a standard capillary active insulation system comprising a calcium silicate insulation that is adhered to the masonry wall by a glue mortar (Häupl et al., 2003; Grunewald et al., 2006; (Vereecken and Roels, 2014b; Vereecken et al., 2015; Scheffler and Grunewald, 2003). Yet, currently, different capillary active interior insulation materials are available, such as autoclaved aerated concrete, wood fibre insulation, etc. Additionally, capillary active insulation systems comprising multiple materials have been developed as well. A more in depth study of the potential differences in hygric properties and in working mechanism is pressed forward. 
Postprint: Vereecken E, Roels S. 2016. Capillary active interior insulation systems for wall retrofitting: A more nuanced story. Accepted for publication in International Journal of Architectural Heritage: Conservation, Analysis, and Restoration 10(5), p. 558-569, DOI: 10.1080/15583058.2015.1009575.

This paper gives a more nuanced description of the main hygric properties and the working principle of the so-called capillary active interior insulation systems. Thereto, the second section of this paper firstly describes the working mechanism of a standard capillary active interior insulation system as explained in the literature. Additionally, a view on some more recently developed 'capillary active' systems is given. In the third, fourth and fifth section, the thermal resistance, the capillary activity and the diffusion resistance of the different systems are discussed. This discussion is illustrated by experimental and numerical simulations. To end, some remarks are made and the main conclusions are drawn. In this way, this paper aims to clear up a number of misconceptions on so-called capillary active interior insulation systems.

\section{CAPILLARY ACTIVE SYSTEMS: MAIN PRINCIPLES}

\subsection{Working mechanism of a standard capillary active system}

Standard capillary active interior insulation systems consist of a calcium silicate (CaSi) layer that is adhered to the masonry wall by a glue mortar. Fig. 1 shows the working principle of such an interior insulation system, as generally explained by the manufacturers and in the literature. During the heating season, the temperature and vapour gradient induces an outward vapour transfer. If the temperature between the glue mortar and the insulation is lower than the dew point, interstitial condensation will occur. Though, calcium silicate has pores in the range of $0.1-1 \mu \mathrm{m}$ which result in a high buffering potential and a large liquid conductivity in the capillary moisture range. As a consequence, capillary active insulation can absorb the liquid water and redistribute it toward the room by a liquid flow which follows the inward capillary 
Postprint: Vereecken E, Roels S. 2016. Capillary active interior insulation systems for wall retrofitting: A more nuanced story. Accepted for publication in International Journal of Architectural Heritage: Conservation, Analysis, and Restoration 10(5), p. 558-569, DOI: 10.1080/15583058.2015.1009575.

pressure gradient. In this way, interstitial condensation can be buffered, at least when a good contact between the masonry wall and the insulation is provided (Scheffler and Grunewald, 2003). If a discontinuity between the masonry wall and the capillary active material occurs, the functionality of the system is nullified, as interstitial condensation can occur at the warm side of the masonry wall and a redistribution by the capillary active material is not possible (see Fig. 2).

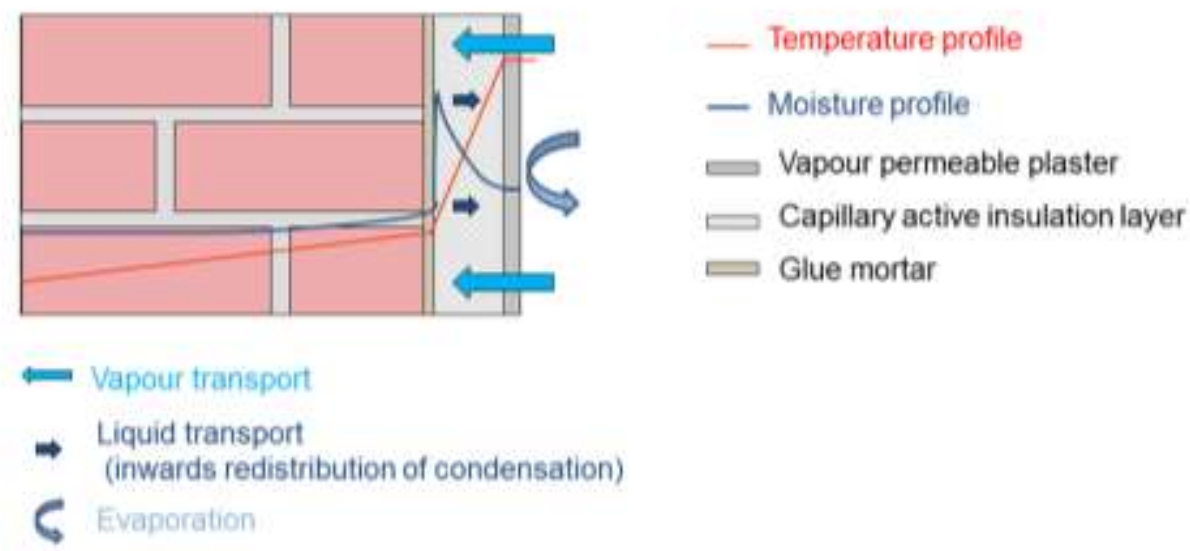

Fig. 1. Working mechanism of a capillary active interior insulation system comprising a calcium silicate layer and a glue mortar.

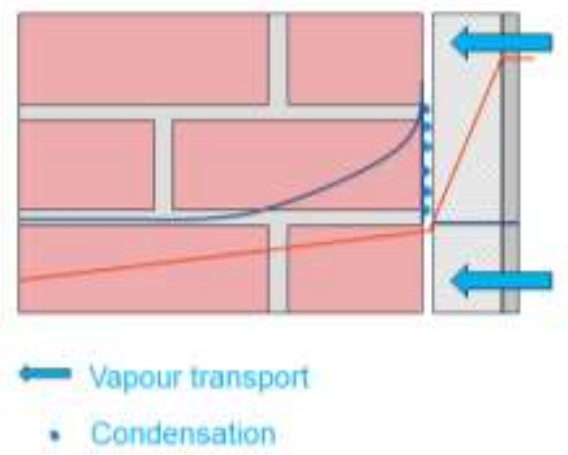

- Temperature profile

- Moisture profile

Vapour permeable plaster

$\rightleftarrows$ Capillary active insulation layer

Fig. 2. Failure of a capillary active interior insulation system due to an air gap between the masonry wall and the insulation system. 
Postprint: Vereecken E, Roels S. 2016. Capillary active interior insulation systems for wall retrofitting: A more nuanced story. Accepted for publication in International Journal of Architectural Heritage: Conservation, Analysis, and Restoration 10(5), p. 558-569, DOI: 10.1080/15583058.2015.1009575.

\subsection{Variations on capillary active systems}

Most studies on capillary active interior insulation systems focus on systems based on calcium silicate (Häupl et al., 2003; Grunewald et al., 2006; Vereecken and Roels, 2014b; Vereecken et al., 2015; Scheffler and Grunewald, 2003). Though, currently, different variants of so-called capillary active interior insulation systems are available. In these systems, the calcium silicate insulation is replaced by, for instance, wood fibre board (WFB), aerated concrete (e.g. Multipor®),... (Stopp et al., 2001; Scheffler, 2001; Kreft et al., 2011). Furthermore, to improve the thermal performance of the insulation system or to modify the working mechanism, recently, capillary active interior insulation systems composed of different materials have been developed as well. Examples of the latter systems are for instance Pavatex Pavadentro® (wood fibre board with embedded mineral functional layer), Remmers IQ-Therm® (PUR in combination with small holes filled with a capillary active material), Calsitherm Xtra® (calcium silicate in combination with PUR, pyrogenic silicas or VIP), etc. (see Fig. 3). Although these different systems are all called capillary active systems, they have widely varying properties and working mechanisms. In the next sections, the thermal resistance and the two main properties generally associated with capillary active insulation systems, i.e. their capillary activity and vapour open character, are discussed. 
Postprint: Vereecken E, Roels S. 2016. Capillary active interior insulation systems for wall retrofitting: A more nuanced story. Accepted for publication in International Journal of Architectural Heritage: Conservation, Analysis, and Restoration 10(5), p. 558-569, DOI: 10.1080/15583058.2015.1009575.

a)

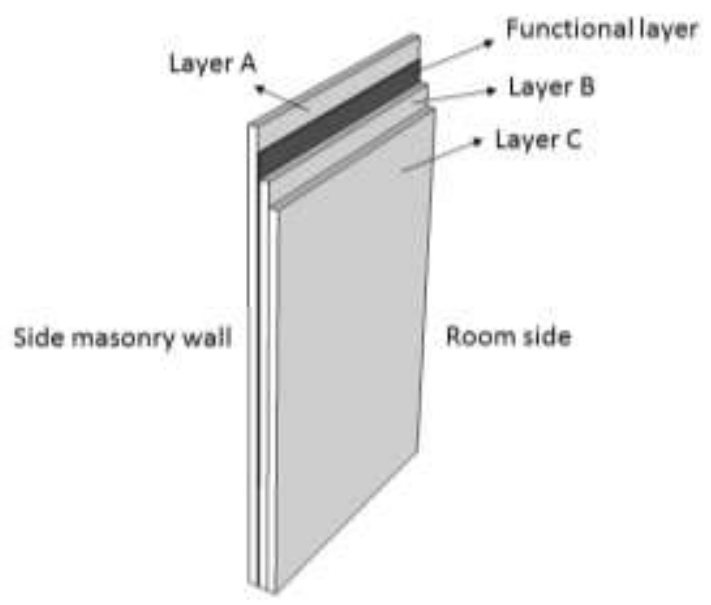

b)

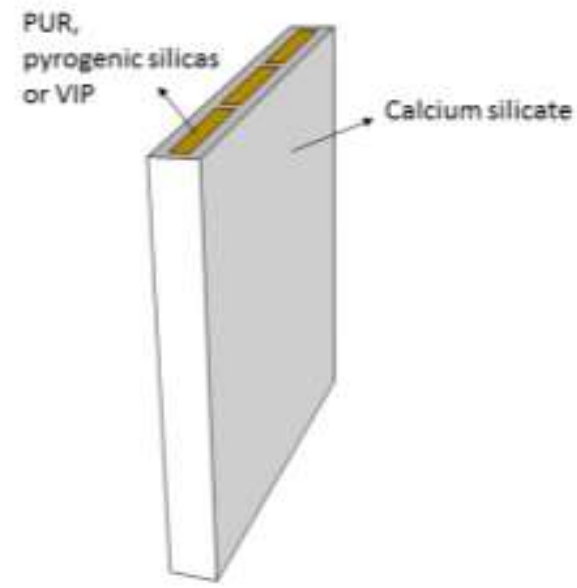

c)

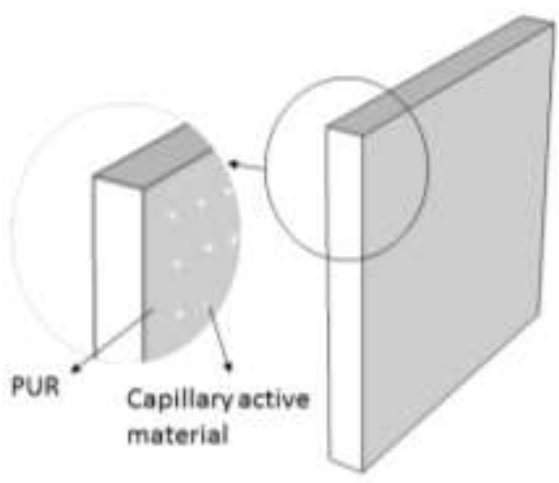

Fig. 3. Schematic representation of multi-material insulation: (a) Pavatex Pavadentro $\AA_{\text {, }}$ (b) Calsitherm Xtra®, (c) Remmers IQ-Therm ${ }^{\circledR}$. 


\section{THERMAL PROPERTIES}

Calcium silicate and other capillary active insulation materials have a much higher thermal conductivity than traditional insulation materials (XPS, PUR, mineral wool,...) have. As a consequence, a rising trend to capillary active systems composed of a traditional - mostly PUR - insulation board in combination with a capillary active material can be observed. A comparison of the dry thermal conductivity of a number of so-called capillary active insulation boards and of two traditional insulation material (PUR and mineral wool) is given in Fig. 4. The equivalent thermal conductivity of the insulaton boards that are composed of a PUR layer and a capillary active material is in the same order of magnitude as the thermal conductivity of the mineral wool. To give an idea of the impact of the differences in thermal conductivity, Fig. 5 shows for each insulation system the insulation thickness required to achieve a thermal resistance of $1.5 \mathrm{~m}^{2} \mathrm{~K} / \mathrm{W}, 2.5 \mathrm{~m}^{2} \mathrm{~K} / \mathrm{W}$ and $3.5 \mathrm{~m}^{2} \mathrm{~K} / \mathrm{W}$. These thicknesses are no commercially available values, but serve solely to make a theoretical comparison. 


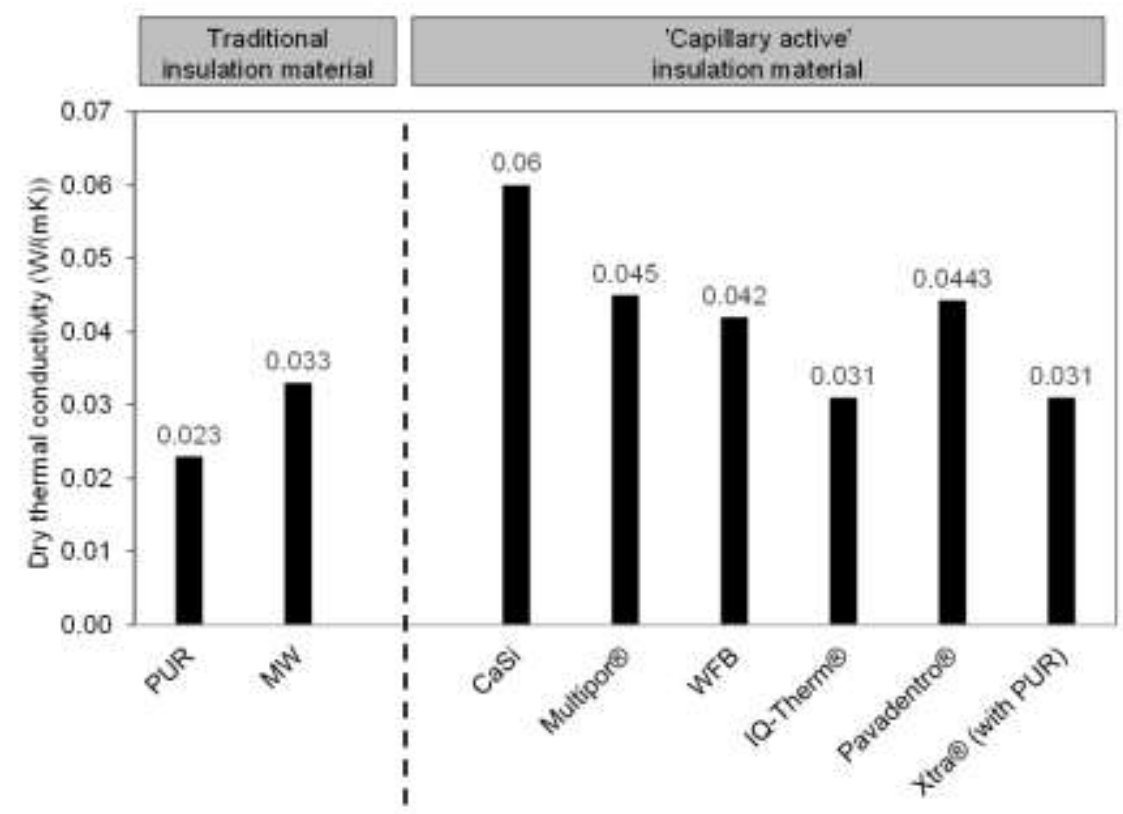

Fig. 4. Indicative values for the dry thermal conductivity of traditional insulation material and the insulation boards used in a number of so-called capillary active systems. For the insulation materials composed of different materials an equivalent thermal conductivity is given. 


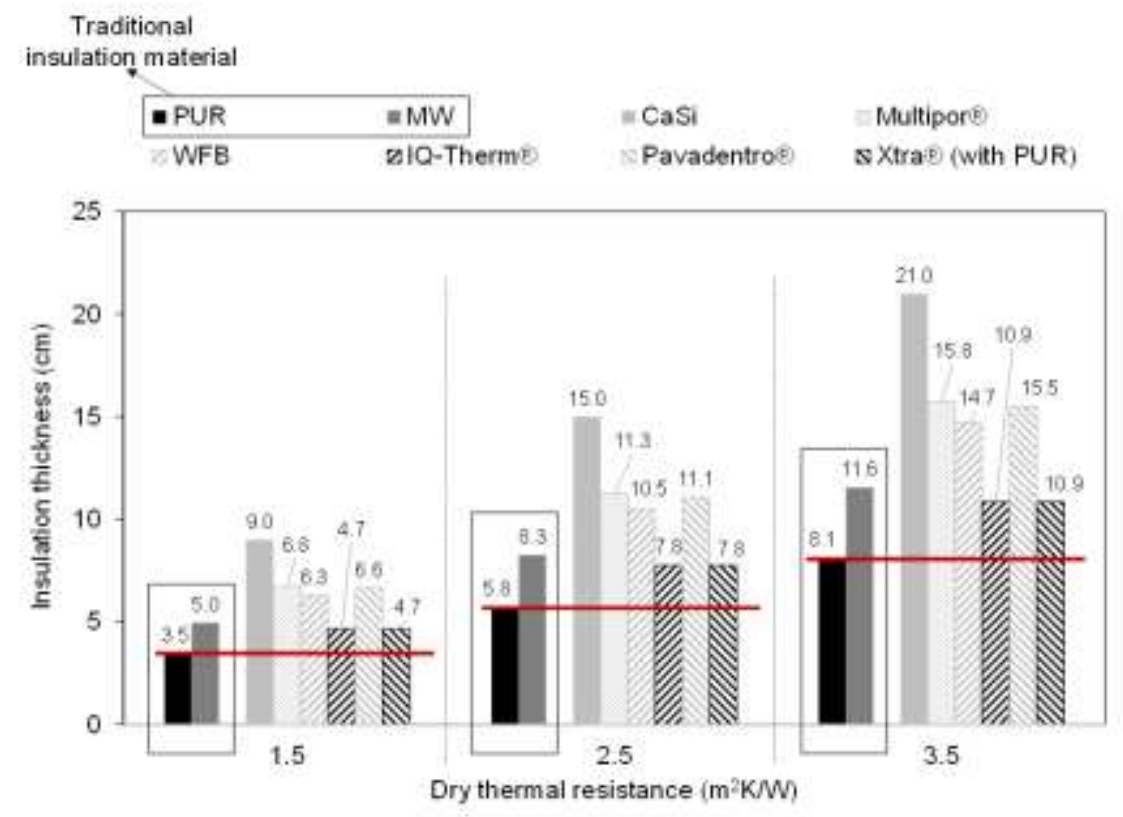

Fig. 5. Required thickness to achieve a specific dry thermal resistance.

It is, however, important to note that those comparison is made for a dry insulation material. Though, as shown in (Vereecken and Roels, 2014b; Vereecken et al., 2015), moisture can be captured in a capillary active material, which results in an increased thermal conductivity. Hence, from a thermal point of view, an efficient traditional insulation board is definitely preferable.

\section{Capillary activity}

An overview of the capillary absorption coefficient of two traditional insulation systems (PUR and mineral wool with smart vapour retarder) and a number of socalled capillary active insulation materials is given in Fig. 6. For some of them, the 
Postprint: Vereecken E, Roels S. 2016. Capillary active interior insulation systems for wall retrofitting: A more nuanced story. Accepted for publication in International Journal of Architectural Heritage: Conservation, Analysis, and Restoration 10(5), p. 558-569, DOI: 10.1080/15583058.2015.1009575.

capillary absorption coefficient of the glue mortar that is proposed by the manufacturer is given as well. It should, however, be kept in mind that the absorption coefficient of the glue mortar is highly influenced by the curing conditions (e.g. absorptivity of the insulation material and the masonry in contact with). Hence, the capillary absorption coefficients given for the glue mortars are only rough indications. For the insulation materials, a large spread can be observed. Multipor ${ }^{\circledR}$ and layer $A$ (side toward the masonry wall, see Fig. 3a) of Pavadentro® have a rather small capillary absorption coefficient and will, hence, less easily transport moisture from the masonry wall toward the room. These materials are hardly to call capillary active materials. Furthermore, it is important to note that the glue mortars have - in exception of the in-house measured capillary absorption coefficient of the glue mortar used in combination with Multipor ${ }^{\circledR}$ - a lower capillary absorption coefficient than found for the insulation material. A low capillary absorption coefficient of the glue mortar should diminish the risk that moisture induced by wind-driven rain will reach the insulation system. Additionally, it avoids a redistribution of potential condensation toward the masonry. 


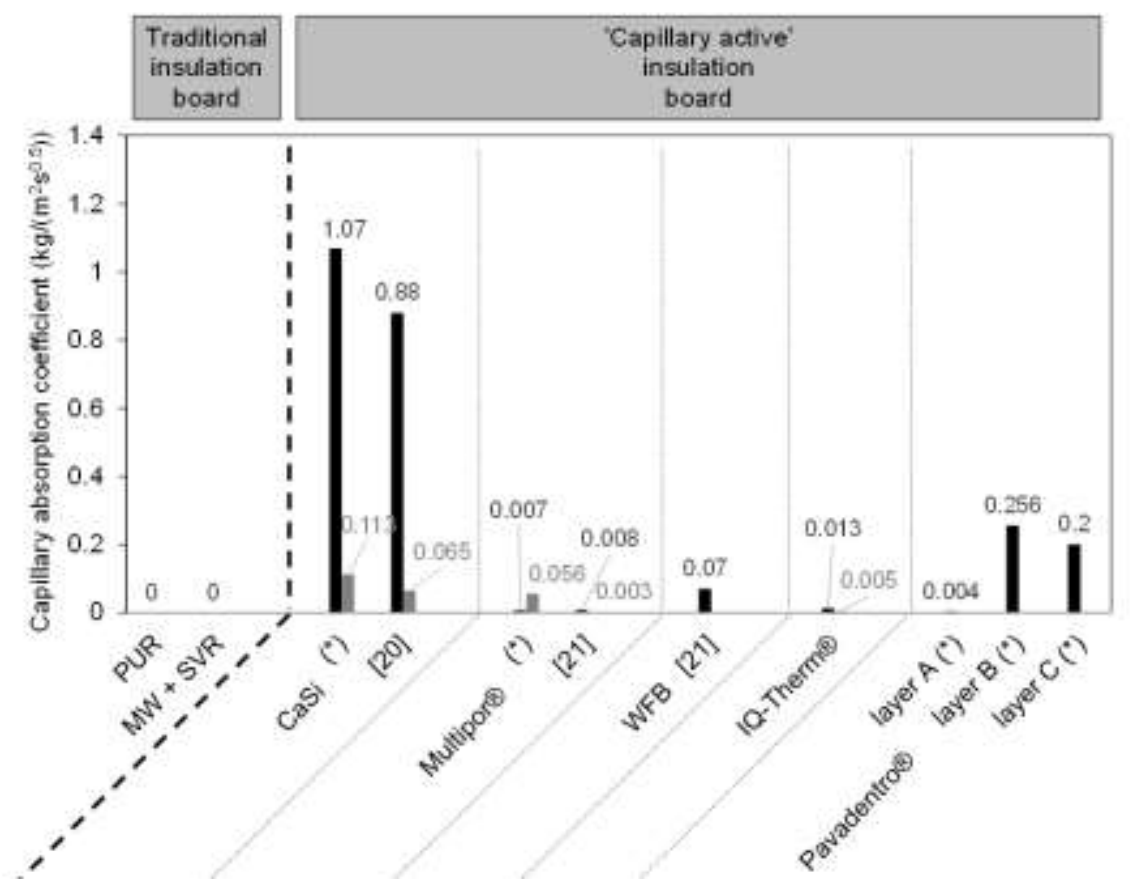

Fig. 6. Indicative values for the capillary absorption coefficient of two traditional insulation materials and a selection of so-called capillary active insulation materials (black bars) and corresponding glue mortars (grey bars). The position of the layers A, B and C of Pavadentro ${ }^{\circledR}$ are indicated in Fig. 3a. The capillary absorption coefficients of the glue mortars can be largely influenced by the curing conditions. The given values are, hence, rough indications. The values based on in-house measurements are indicated by $\left(^{*}\right)$.

The difference in moisture response between a capillary active system with a high and a low capillary absorption coefficient is shown in Fig. 7. This figure presents the moisture distribution in a capillary active system comprising (a) a calcium silicate and (b) a Multipor ${ }^{\circledR}$ insulation board, and this during a steady-state winter condition simulated in a hot box-cold box experiment (Vereecken, 2013; Vereecken and Roels, 2014a). In this hot box-cold box experiment, the test walls were positioned between a 
hot box $\left(35^{\circ} \mathrm{C}\right.$ and $\left.85 \% \mathrm{RH}\right)$ and a cold box $\left(2{ }^{\circ} \mathrm{C}\right.$ and $\left.45 \% \mathrm{RH}\right)$. After the start of the experiment, the boxes were opened at regular time steps to make X-ray images of the test walls. Next, by use of the X-ray projection method (Roels and Carmeliet, 2006) the moisture distribution was analysed. In both insulation systems, due to interstitial condensation or due to outward vapour diffusion, the glue mortar captured a large amount of moisture. In the insulation materials, a moisture increase can be observed. For the interior insulation with a calcium silicate (Fig. 7a), the moisture is redistributed to the inside and from the cold side to the warm side of the insulation a gradual moisture decrease can be observed, whereas for the Multipor $\AA$ insulation board (Fig. 7b) - with a lower capillary absorption coefficient - this is less pronounced. In the latter case, a moisture increase in the insulation material is solely visible at the side of the glue mortar. 
a)

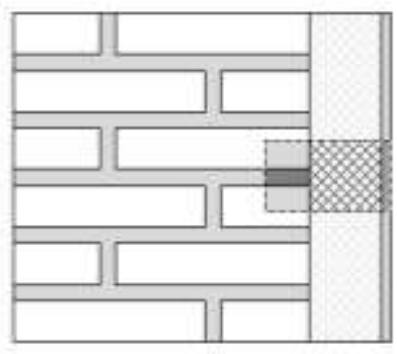

b)

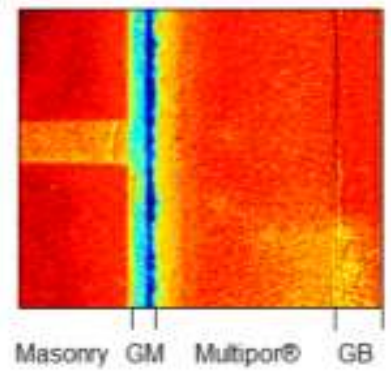

c)

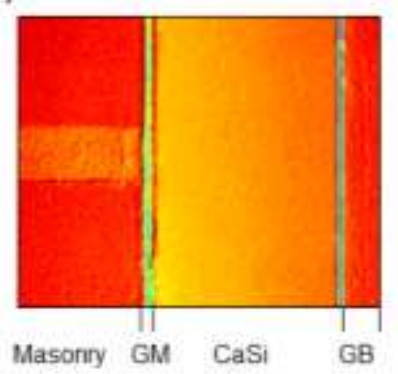

Negligible

increase in

moisture

content
High

increase in moisture content

Fig. 7. Moisture distribution in a capillary active interior insulation system comprising (b) calcium silicate and (c) Multipor ${ }^{\circledR}$ insulation board, as measured in a hot box-cold box experiment (Vereecken and Roels, 2014a). At the figure solely the main field of interest indicated by the rectangle in (a) is shown. So, from left to right, the increase in moisture content of part of the masonry wall, glue mortar (GM), insulation and gypsum board (GB) is plotted.

The moisture profiles given in Fig. 7 clearly show the difference in behaviour of both materials but it must be noticed that they have been obtained during a hot box-cold box experiment that was performed for rather severe or even unrealistic boundary 
Postprint: Vereecken E, Roels S. 2016. Capillary active interior insulation systems for wall retrofitting: A more nuanced story. Accepted for publication in International Journal of Architectural Heritage: Conservation, Analysis, and Restoration 10(5), p. 558-569, DOl: 10.1080/15583058.2015.1009575.

conditions $\left(35^{\circ} \mathrm{C}\right.$ and $85 \%$ relative humidity in the room, $2{ }^{\circ} \mathrm{C}$ and $45 \%$ outside). Furthermore, based on this experiment solely a qualitative indication was achieved. Thereto, the experimental study is extended by a numerical study (Vereecken, 2013) performed with HAMFEM (Janssen et al., 2007), an in-house program that solves the conservation equations of energy and mass by means of a finite element method. In this way, the hygric behaviour for a more realistic winter condition $\left(20^{\circ} \mathrm{C}\right.$ and $50 \%$ relative humidity in the room, $0{ }^{\circ} \mathrm{C}$ and $85 \%$ outside) and for a slightly modified wall structure (an interior plaster layer was used instead of a gypsum board, since this is the common practice when dealing with capillary active systems) was investigated. A similar behaviour was found in the numerical study, as shown in Fig. 8. When calcium silicate is used, the gradual course of the moisture content in the insulation system is clearly visible. No over-hygroscopic moisture occurs. On the other hand, for Multipor ${ }^{\circledR}$, due to a lower liquid conductivity and in less extent to a lower vapour diffusion resistance factor (see Fig. 9), more moisture is stored in the glue mortar. The moisture redistribution toward the room occurs less easily, as also observed based on the steeper moisture profile in the insulation material. A higher moisture content and relative humidity in the masonry is certainly observed. Over-hygroscopic moisture occurs, which includes a risk for e.g. wooden beam ends. Note also the higher moisture content in the plaster layer, which is due to its hygroscopic behaviour. 
Postprint: Vereecken E, Roels S. 2016. Capillary active interior insulation systems for wall retrofitting: A more nuanced story. Accepted for publication in International Journal of Architectural Heritage: Conservation, Analysis, and Restoration 10(5), p. 558-569, DOI: 10.1080/15583058.2015.1009575.

a)

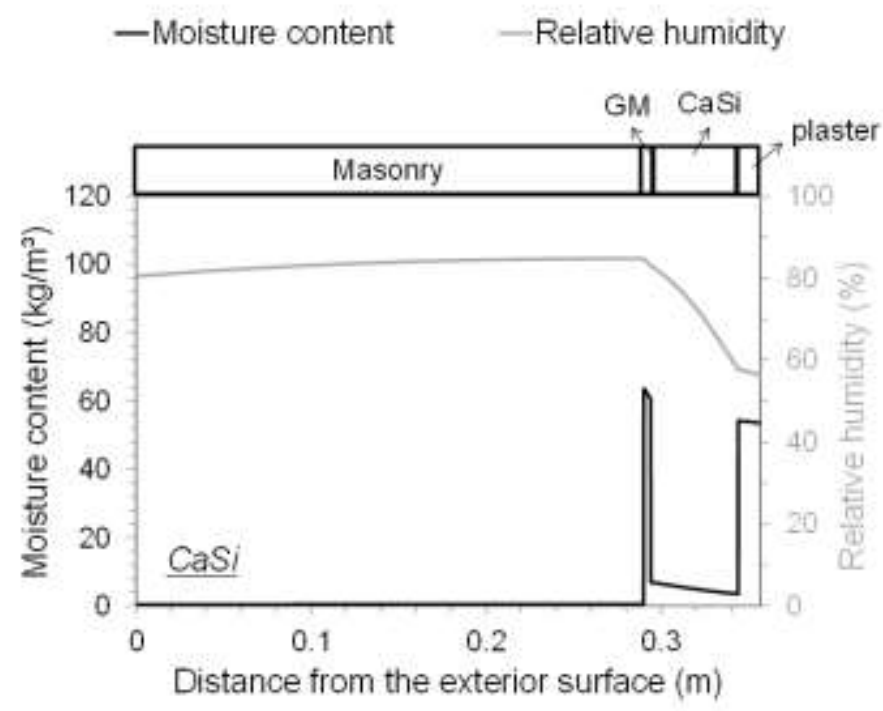

b)

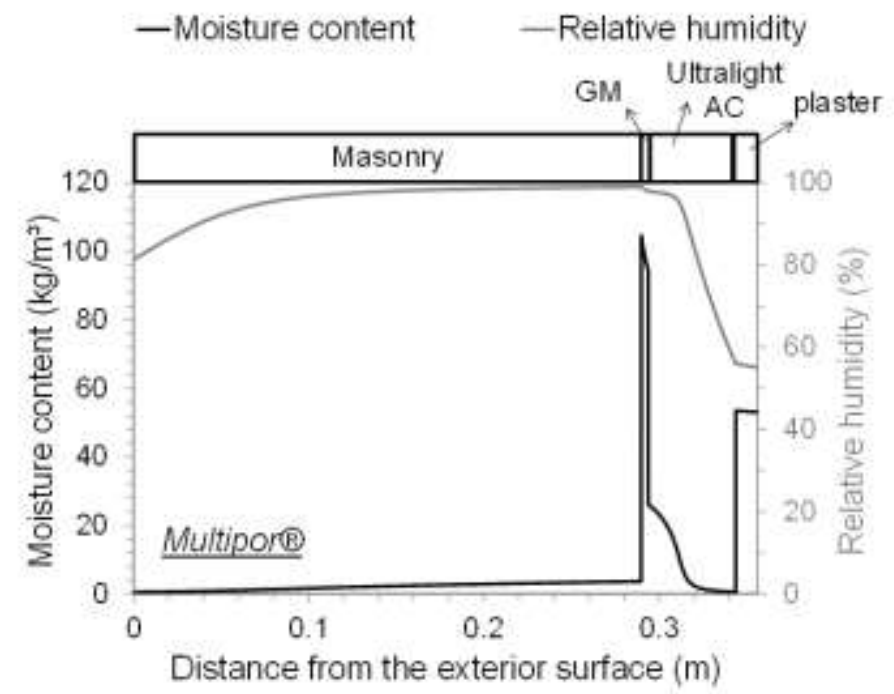

Fig. 8. Moisture profiles and relative humidity courses in a wall assembly with (a) calcium silicate and (b) ultralight aerated concrete (after 400 days). 


\section{DIFFUSION OPEN CHARACTER}

To allow an inward drying of the moisture in the masonry wall, the interior insulation system should be vapour open. As found for the capillary activity of the capillary active systems, however, the vapour diffusion resistance varies among the different systems available on the market. To illustrate this difference, Fig. 9 shows the sddryvalue for a number of insulation systems (with inclusion of glue mortar layers and finishing layers), all with a dry thermal resistance equal to $2.5 \mathrm{~m}^{2} \mathrm{~K} / \mathrm{W}$. The vapour tight insulation parts in the IQ-Therm ${ }^{\circledR}$ and the Calsitherm Xtra® provide a clearly higher sd-value. The sddry-value of the latter systems is - for a thermal resistance equal to $2.5 \mathrm{~m}^{2} \mathrm{~K} / \mathrm{W}$ - approximately 3 times larger than found for the standard system comprising a calcium silicate board. For a higher thermal resistance, the difference between the sddry-value achieved with IQ-Therm® or Calsitherm Xtra® and with more traditional systems comprising a mineral wool with smart vapour retarder will get smaller. 


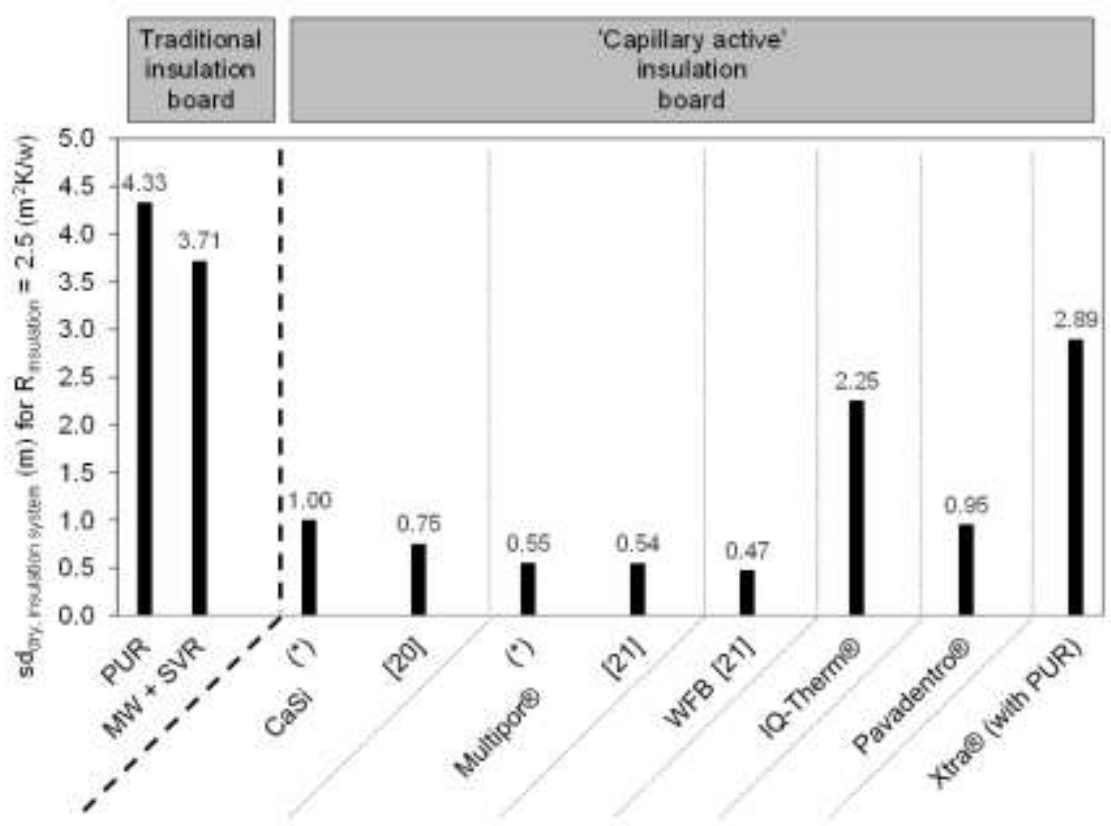

Fig. 9. Dry vapour diffusion resistance factor of a selection of so-called capillary active insulation systems (for IQ-Therm ${ }^{\circledR}$ and Calsitherm Xtra ${ }^{\circledR}$, an equivalent one-dimensional value is calculated). The values based on in-house measurements are indicated by $\left(^{*}\right)$.

The impact of the enlarged vapour diffusion resistance induced by incorporating PUR insulation in a 'capillary active' insulation system, and of the impossibility to transport liquid by these materials, is shown based on a numerical simulation. A comparison is made between the moisture profile and relative humidity course for a wall assembly with (a) a traditional $6.68 \mathrm{~cm}$ PUR insulation board with 1.25 gypsum board, (b) a $17.6 \mathrm{~cm}$ calcium silicate adhered to the wall with a glue mortar and at the room side finished with a $1 \mathrm{~cm}$ plaster layer and (c) $9 \mathrm{~cm}$ Calsitherm Xtra® system, which all result in a same dry thermal resistance $\left(2.9 \mathrm{~m}^{2} \mathrm{~K} / \mathrm{W}\right)$. The analysis is performed for a south-west oriented wall of a fictitious $10 \times 10 \times 10 \mathrm{~m}^{3}$ building located in Essen 
Postprint: Vereecken E, Roels S. 2016. Capillary active interior insulation systems for wall retrofitting: A more nuanced story. Accepted for publication in International Journal of Architectural Heritage: Conservation, Analysis, and Restoration 10(5), p. 558-569, DOI: 10.1080/15583058.2015.1009575.

(Germany), which is exposed to wind-driven rain. The indoor temperature and relative humidity are set at $20^{\circ} \mathrm{C}$ and $50 \%$ relative humidity, respectively. More detailed boundary conditions can be found in (Vereecken and Roels, 2014b).

As an illustrative example of the observed differences, Fig. 10 compares the moisture profile and relative humidity course on November $2^{\text {nd }} 6 \mathrm{PM}$. Similar to the conclusions drawn in (Vereecken and Roels, 2014b; Vereecken et al., 2015), due to an inward moisture redistribution by the calcium silicate board (Fig. 10b), the moisture content in the masonry wall is lower than found if a vapour tight system (Fig. $10 a)$ is applied. In this way, potential moisture related failure in the masonry wall and eventually in wooden beam ends might be avoided. An interior insulation system composed of a combination of a calcium silicate and a PUR board (cfr. Xtra®) results - compared to a homogenous vapour tight system - in a reduction of the moisture content in the brick as well. The moisture content in the glue mortar and in the calcium silicate layer near the masonry wall is, however, higher. Caution is required, since an inward moisture redistribution via the calcium silicate (see profile A in Fig. 10c) could result in an increase of the relative humidity at the interior surface, as indicated in Fig. 11. Such a potential risk on a too high surface relative humidity seems indeed not completely impossible, as the manufacturer suggests the use of a special mould resistant finishing layer. Additionally, the use of a glue mortar and capillary active insulation material resistant to frost damage might be recommended in severe climates, as the risk of achieving subfreezing temperatures in combination with a high moisture content in these layers increases due to the lower thermal conductivity and the hygric properties of the PUR-board. 
Postprint: Vereecken E, Roels S. 2016. Capillary active interior insulation systems for wall retrofitting: A more nuanced story. Accepted for publication in International Journal of Architectural Heritage: Conservation, Analysis, and Restoration 10(5), p. 558-569, DOI: 10.1080/15583058.2015.1009575.

a)

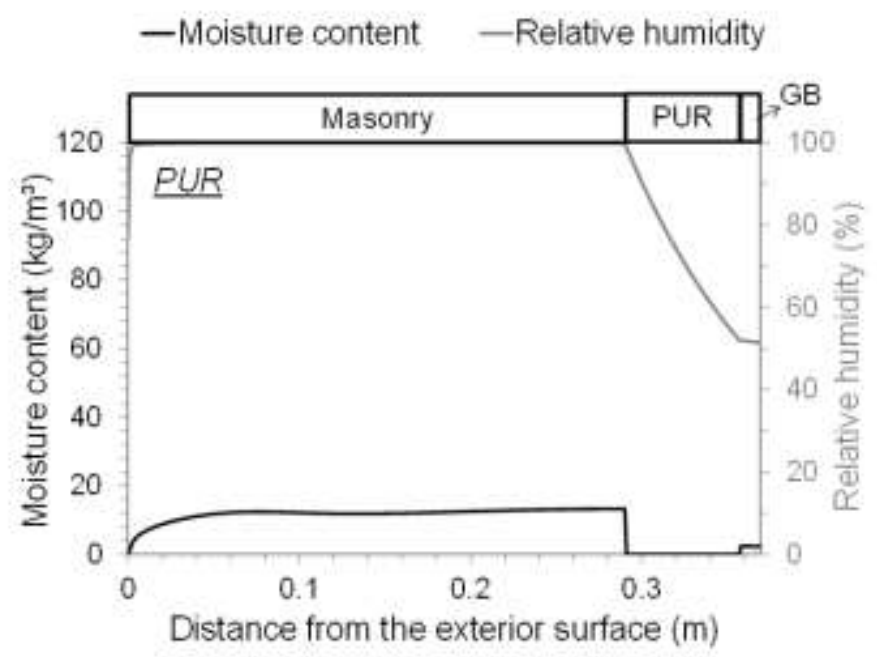

b)

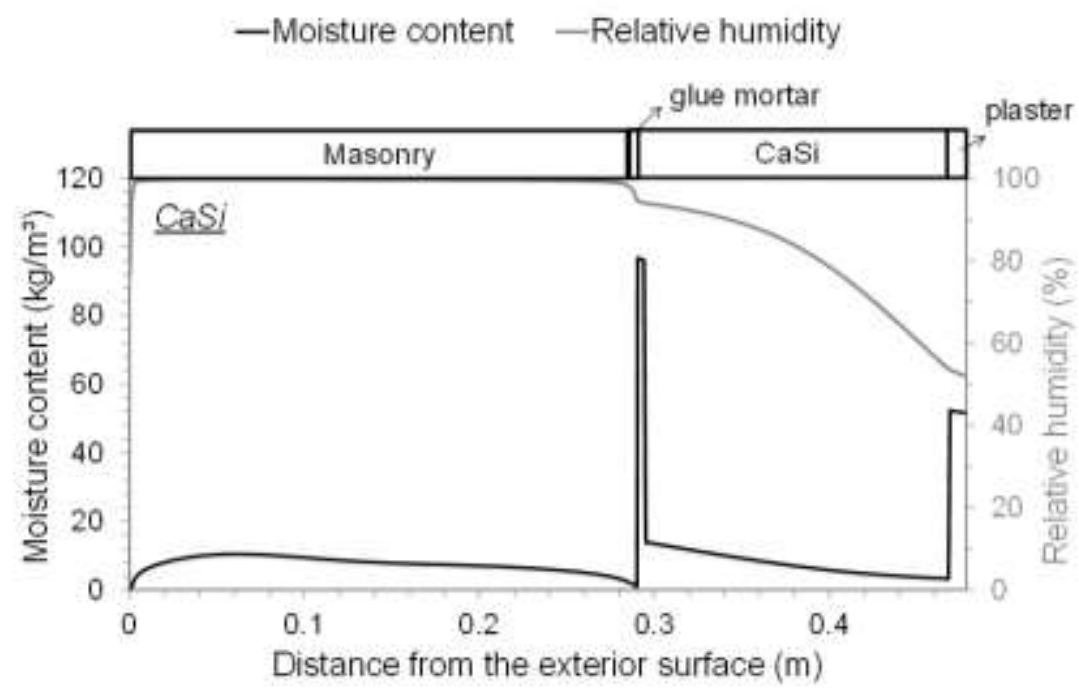


Postprint: Vereecken E, Roels S. 2016. Capillary active interior insulation systems for wall retrofitting: A more nuanced story. Accepted for publication in International Journal of Architectural Heritage: Conservation, Analysis, and Restoration 10(5), p. 558-569, DOI: 10.1080/15583058.2015.1009575.

c)

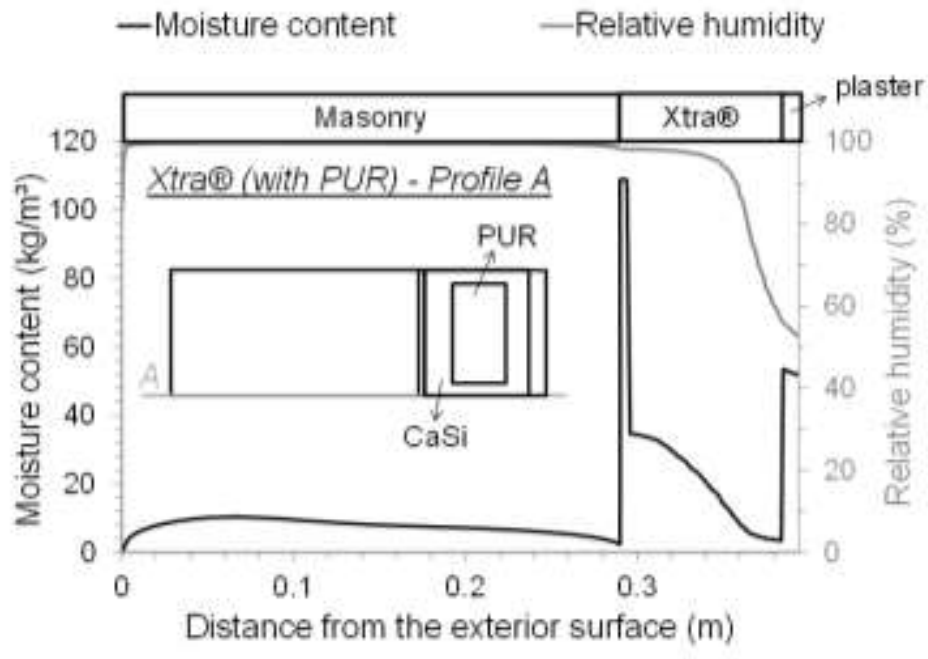

d)

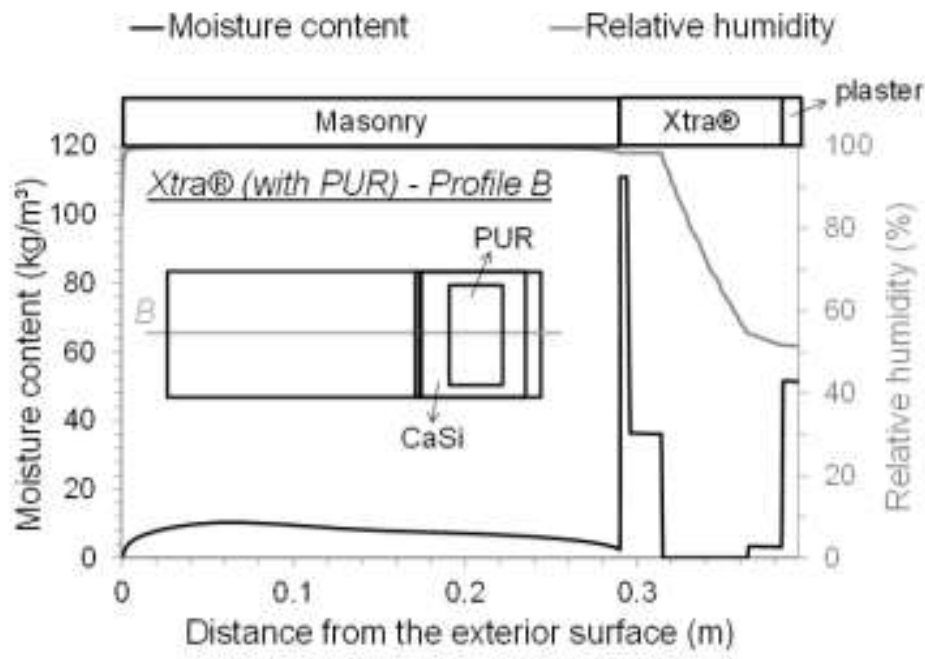

Fig. 10. Moisture and relative humidity profile for November $2^{\text {nd }} 6$ PM: (a) PUR, (b) CaSi, (c,d) calcium silicate with an embedded PUR-board as found in Xtra®. 


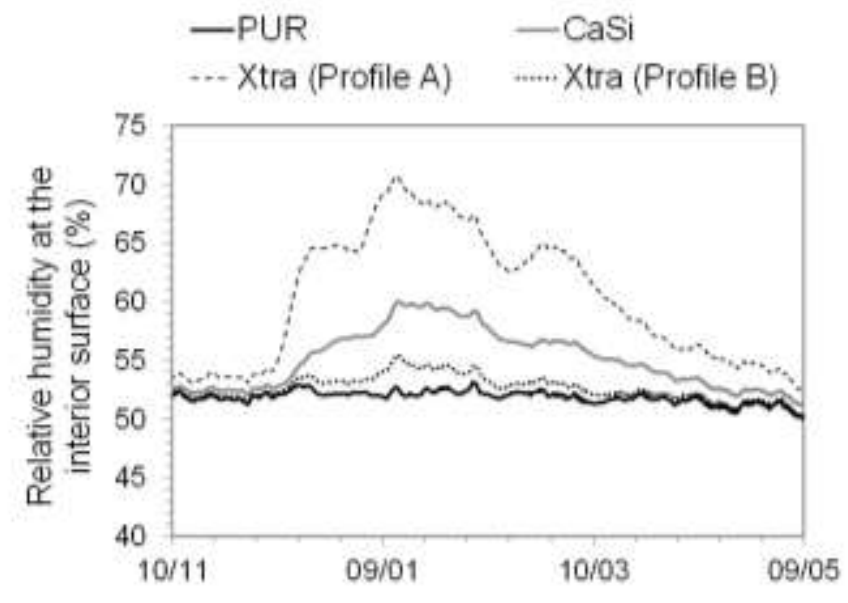

Fig. 11. Relative humidity at the interior surface (Profile $A$ and $B$ are indicated in the inset in Fig. 10c,d).

In addition to the vapour diffusion resistance of the entire insulation system, the vapour diffusion resistance of the individual materials in the systems determines the working mechanism of the system. The glue mortar used to stick the insulation board to the masonry wall typically has a somewhat higher dry vapour diffusion resistance factor ( $\mu$ dry,glue mortar is generally between 11 and 35) than the insulation material ( $\mu$ dry,insulation is generally between 3 and 6 for the materials that do not comprise a vapour tight material). This in combination with the higher thermal conductivity of the glue mortar, forces potential condensation to occur between the glue mortar and the insulation material instead of near the masonry wall.

Scheffler and Grunewald (2003), furthermore, used the impact of a difference in diffusion resistance (and thermal conductivity) of the materials in the interior 
Postprint: Vereecken E, Roels S. 2016. Capillary active interior insulation systems for wall retrofitting: A more nuanced story. Accepted for publication in International Journal of Architectural Heritage: Conservation, Analysis, and Restoration 10(5), p. 558-569, DOI: 10.1080/15583058.2015.1009575.

insulation system to propose a two-layered capillary active interior insulation system that should ensure the functionality of the capillary interior insulation system, even if an air gap between the original masonry wall and the insulation system occurs. This system comprises a retarder layer at the side of the masonry wall and an actual insulation layer at the room side. The aim of the two-layered system was to force the interstitial condensation to occur between the retarder layer and the insulation layer instead of at the masonry wall. To locate the interstitial condensation plane between the retarder and the insulation layer, for the actual insulation material, a low thermal conductivity, a high liquid conductivity and a low vapour diffusion resistance are preferable, as indicated in (Scheffler and Grunewald, 2003). For the retarder layer, a higher thermal conductivity, a lower capillary conductivity and a higher vapour diffusion resistance are recommended.

A multi-layered capillary active interior insulation system that pursues to get the condensation plane in the insulation system is commercially available as well. This system comprises three wood fibre insulation layers of $2 \mathrm{~cm}$ thick and an embedded vapour control barrier, which is called the functional layer. The two wood fibre layers toward the room side are glued to each other and are separated from the third layer by the functional layer. The working principles of this system as described by the manufacturer (EP 1900884 A1, 2008) is explained based on Fig. 12. During the heating season, water vapour will be transported in the insulation system. The functional layer restricts the vapour transport. A condensation plane arises at the functional layer. Due to the capillary active forces of the wood fibre board, potential interstitial condensation can be redistributed toward the room side. This working 
Postprint: Vereecken E, Roels S. 2016. Capillary active interior insulation systems for wall retrofitting: A more nuanced story. Accepted for publication in International Journal of Architectural Heritage: Conservation, Analysis, and Restoration 10(5), p. 558-569, DOI: 10.1080/15583058.2015.1009575.

mechanism explains the lower capillary absorption coefficient of layer $A$ of the Pavadentroß system (see Fig. 6).

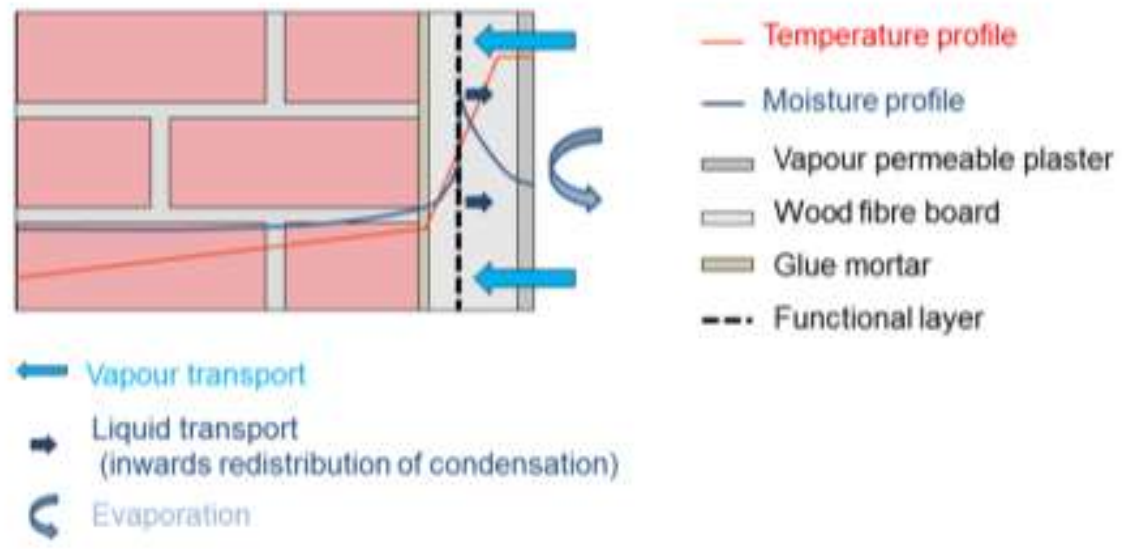

Fig. 12. Working principle of wood fibre insulation board with an embedded functional layer as explained by the manufacturer (EP 1900884 A1, 2008).

In what follows, the working mechanism of a multi-layered interior insulation system comprising three wood fibre insulation layers of $2 \mathrm{~cm}$ thick and a vapour control barrier, and thus based on the system mentioned above, is viewed in more detail. Based on the moisture distribution measured during a hot box-cold box experiment (Vereecken, 2013), it can be concluded that the intended working mechanism as described above is not obtained, as shown in Fig. 13. Near the functional layer, at the side closest to the room, the moisture content has increased. Though, at the warm side of the functional layer no inward moisture redistribution is found. Additionally, in contrast to the working principle explained by the manufacturer, moisture is captured 
by the glue mortar and redistributed to the insulation layer. Moreover, the accumulated moisture in the wood fibre board at the cold side of the insulation seems to be larger than found next to the functional layer. The blue line (not over the full height of the material) between the two wood fibre layers at the warm side of the functional layer can be attributed to the glue used to stick the two most inward wood fibre boards to each other. Note also that in this experiment a glue mortar was used to stick the wood fibre board on the masonry wall. As explained by Scheffler and Grunewald (2003), an interstitial condensation plane in the insulation material should avoid that the capillary active system does not work because of a disconnection between the masonry wall and the insulation system. To evaluate this, in a second hot box-cold box experiment no adhesive was used between the insulation material and the masonry wall (Vereecken, 2013). Also in this case a moisture increase was found in the wood fibre layer near the masonry wall. 


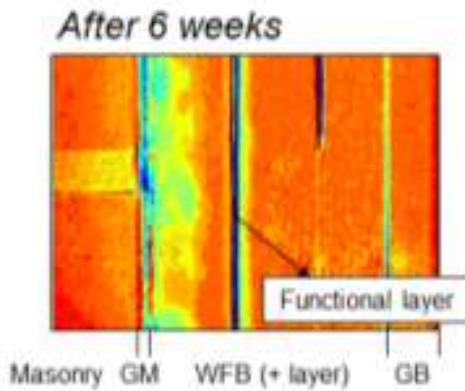

\section{Negligible}

increase in

moisture

content

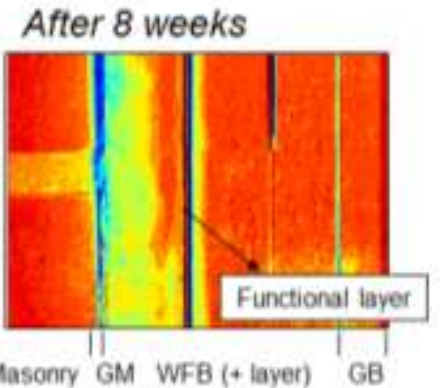

Masonry GM WFB (+ layer) GB

Fig. 13. Evolution of the moisture distribution in the wall with wood fibre board with embedded functional layer as measured in a hot box-cold box experiment (Vereecken and Roels, 2014a). At the figure, solely the main field of interest is shown (rectangle in Fig. 7a). So, from left to right, the increase in moisture content of part of the masonry wall, glue mortar (GM), insulation and gypsum board (GB) is plotted.

The numerically determined moisture profile and relative humidity course in the wall assembly retrofitted with a multi-layered wood fibre board comprising an embedded vapour retarder are shown in Fig. 14a. The simulation is performed for a steady-state winter condition $\left(20{ }^{\circ} \mathrm{C}\right.$ and $50 \%$ relative humidity in the room, $0{ }^{\circ} \mathrm{C}$ and $85 \%$ outside). The vapour resistance of the functional layer in the current study is based on an in-house dry/wet cup measurement performed on the functional layer of the Pavadentro®. For this layer, a relative humidity dependent vapour resistance was measured (Vereecken, 2013). Based on the numerical simulation, it can be concluded that like for the hot box-cold box experiment also for realistic boundary 
Postprint: Vereecken E, Roels S. 2016. Capillary active interior insulation systems for wall retrofitting: A more nuanced story. Accepted for publication in International Journal of Architectural Heritage: Conservation, Analysis, and Restoration 10(5), p. 558-569, DOI: 10.1080/15583058.2015.1009575.

conditions, the working mechanism differs from the working principle explained in Fig. 12. In the simulation, the interstitial condensation does not occur at the functional layer but between the masonry wall and the insulation board. Moisture is accumulated in both the wood fibre insulation and the masonry wall. Furthermore, a high relative humidity and moisture content in the masonry wall can be observed.

To achieve a better understanding of this behaviour, Fig. 14 shows the influence of the vapour resistance of the layer embedded in the wood fibre board. To this end, the functional layer is removed (Fig. 14b) or replaced by a PE-foil (Fig. 14c). The absence of the functional layer seems to have no influence on the obtained moisture profile and relative humidity course found after equilibrium. This indicates that the vapour resistance of the functional layer is - at least after some time - too small to have an influence. When interstitial condensation occurs near the functional layer, which is pursued, the humidity-dependent vapour resistance will drop. The functional layer loses its capacity to restrict the vapour transport. Hence, the interface between the masonry wall and the insulation system becomes the potential interstitial condensation plane. A traditional PE-foil (Fig. 14c) embedded in the wood fibre insulation system seems to result in a condensation plane near the PE-foil, and thus in the wood fibre board as intended by the multi-layered system with an embedded functional layer. Though, by applying such a PE-foil, the advantage of a drying out of the masonry wall toward the room is of course not valid anymore. 
Postprint: Vereecken E, Roels S. 2016. Capillary active interior insulation systems for wall retrofitting: A more nuanced story. Accepted for publication in International Journal of Architectural Heritage: Conservation, Analysis, and Restoration 10(5), p. 558-569, DOI: 10.1080/15583058.2015.1009575.

a)

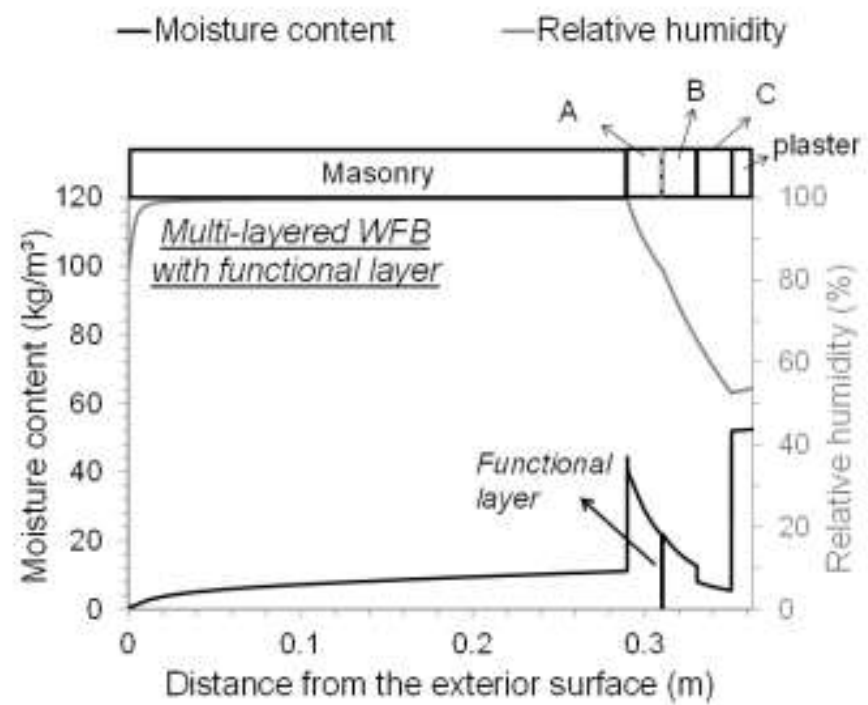

b)

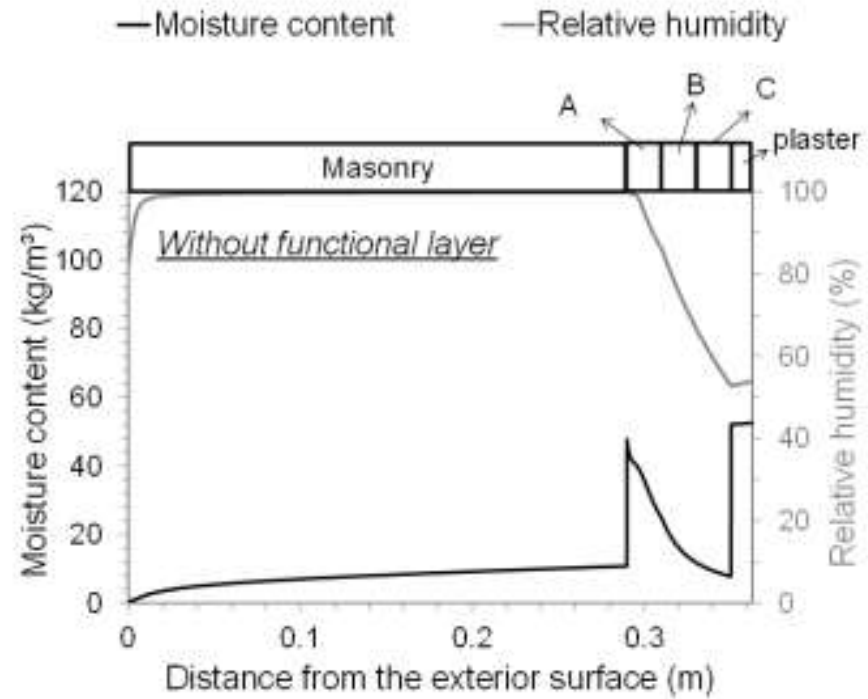


c)

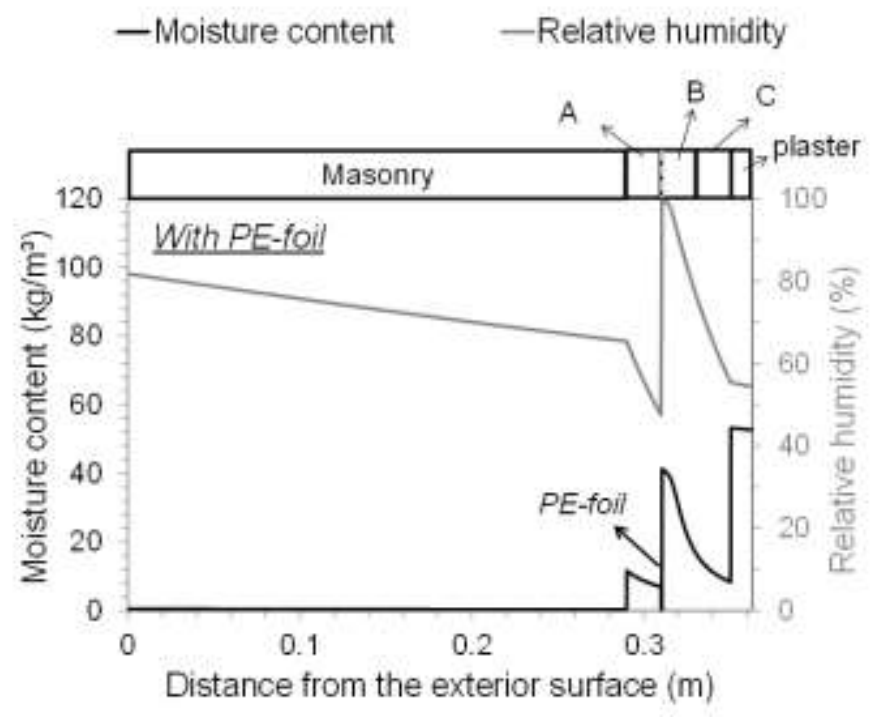

Fig. 14. Moisture profiles and relative humidity courses in a wall assembly with a multi-layered interior wood fibre insulation system (after $\mathbf{4 0 0}$ days): influence of a functional layer.

\section{DISCUSSION AND CONCLUSION}

The current work discussed the working mechanism of so-called capillary active interior insulation systems. These systems are nowadays often promoted since they might reduce the risk on potential damage patterns associated with interior insulation. Previous studies (Vereecken and Roels, 2014b; Vereecken et al., 2015), however, addressed already some points of attention. It should, for instance, be kept in mind that to avoid such problems moisture is stored in the glue mortar or capillary active 
Postprint: Vereecken E, Roels S. 2016. Capillary active interior insulation systems for wall retrofitting: A more nuanced story. Accepted for publication in International Journal of Architectural Heritage: Conservation, Analysis, and Restoration 10(5), p. 558-569, DOI: 10.1080/15583058.2015.1009575.

insulation material. This moisture storage has an adverse impact on the thermal performance. Additionally, the buffered moisture that is transported toward the room can increase the interior surface and room relative humidity. As a consequence, instead of a more stable indoor climate achieved by the high hygric buffering capacities of capillary active materials, an increase of the indoor relative humidity might be possible.

At present, several types of so-called capillary active systems are on the market, showing widely varying hygric properties. In the current paper it was shown that some of these systems (e.g. Multipor $\AA$ ) have a rather low capillary absorption coefficient (and thus liquid permeability). These systems are hardly to call capillary active systems. Additionally, a higher diffusion resistance of the glue mortar layer and potential additional layers or materials used to improve the thermal performance of the system makes the insulation system less vapour open as originally asserted. In this respect, an equivalent vapour diffusion resistance in the same order of magnitude as obtained by a traditional vapour retarder could be achieved. The vapour open character should, thus, for some of the systems be taken with a grain of salt. Furthermore, it is shown that caution is required when applying systems composed of a combination of a vapour tight and a capillary active material. Based on all this, it can be concluded that not all systems currently designated as capillary active systems operate as could be expected from a capillary active system. Additionally, a humidity dependent vapour retarder in the insulation material was shown to not avoid over-hygroscopic moisture near the masonry wall. 
Postprint: Vereecken E, Roels S. 2016. Capillary active interior insulation systems for wall retrofitting: A more nuanced story. Accepted for publication in International Journal of Architectural Heritage: Conservation, Analysis, and Restoration 10(5), p. 558-569, DOI: 10.1080/15583058.2015.1009575.

To end, it should be noted that a lower liquid permeability and hence a less capillarity of the insulation material does not necessarily imply an adverse performance, as this could avoid a too high interior surface or room relative humidity for walls exposed to a high wind-driven rain load. An optimisation of the interior insulation systems strongly demands a more in depth study.

\section{ACKNOWLEDGEMENTS}

The results within this paper have been partially obtained within the IWT VIS-Traject 'Renofase' (IWT 120784) funded by the Flemish Government and KUL OT/09/23 'Toward a reliable application of interior insulation for the retrofit of existing buildings' funded by KU Leuven. These financial supports are gratefully acknowledged.

\section{REFERENCES}

Bullen, P.A. 2007. Adaptive reuse and sustainability of commercial buildings. Facilities 25(1/2):20-31.

EP 1900884 A1. 2008. Europäische petentanmeldung, Holzweichfaserplatte für die raumseitige Dämmung, 19.03.2008 Patentblatt 2008/12.

Geva, A. 1998. Energy simulation of historic buildings: St. Louis Catholic Church, Castroville, Texas. APT Bulletin, Vol. 29(1):36-41.

Grunewald, J., Ruisinger, U. and Häupl, H. 2006. The Rijksmuseum Amsterdam hygrothermal analysis and dimensioning of thermal insulation. In Research in 
Postprint: Vereecken E, Roels S. 2016. Capillary active interior insulation systems for wall retrofitting: A more nuanced story. Accepted for publication in International Journal of Architectural Heritage: Conservation, Analysis, and Restoration 10(5), p. 558-569, DOI: 10.1080/15583058.2015.1009575.

Building Physics and Building Engineering. Edited by Fazio, Ge, Rao, Desmarais, Taylor \& Francis group, London, pp. 345-52.

Häupl, P., Jurk, K. and Petzold, H. 2003. Inside thermal insulation for historical facades. In Research in Building Physics. Edited by Carmeliet, Hens, Vermeir. Lisse: A.A. Balkema Publishers, pp. 463-9.

Häupl. P. 2010. Bauphysik Kalender. Innendämmung von Außenbauteilen.

Janssen, H., Blocken, B., Carmeliet, J. 2007. Conservative modelling of the moisture and heat transfer in building components under atmospheric excitation, Int $\mathrm{J}$ Heat Mass Tran 50:1128-40.

Kreft, O., Straube, B., and Schoch, T. 2011. Internal thermal insulation with light weight autoclaved aerated concrete. In Proceedings of $5^{\text {th }}$ International Autoclaved Aerated Concrete Conference. Bydgoszcz, Poland, September 14-17, p.251-256.

Maurenbrecher, A.H.P., Shirtliffe, C.J., Rousseau, M.Z. and Saïd, M.N.A. 1998. Monitoring the hygrothermal performance of a masonry wall with and without thermal insulation. In Proceedings of the $8^{\text {th }}$ Canadian Masonry Symposium, Jasper, Alberta.

Nicolai, A., Grunewald, J., and Fechner, H. 2010. DELPHIN: Simulation program for coupled heat, air, moisture, salt and VOC transport. www.bauklimatikdresden.de/delphin (accessed 14 May 2014). 
Postprint: Vereecken E, Roels S. 2016. Capillary active interior insulation systems for wall retrofitting: A more nuanced story. Accepted for publication in International Journal of Architectural Heritage: Conservation, Analysis, and Restoration 10(5), p. 558-569, DOI: 10.1080/15583058.2015.1009575.

Padfield, T., Larsen, P.K, Jensen, L.A. and Ryhl-svendsen, M. 2007. The potential and limits for passive air conditioning of museums, stores and archives, In Proceedings of 'Museum Microclimates', Copenhagen, Denmark.

Pauliny, P. and Varga, T. 2014. When less is more. Reducing energy consumption of historical buildings. In Buildings and Environment 2014 Proceedings.

Philokyprou, M. 2014. Adaptation of new university uses in old buildings: the case of rehabilitation of listed buildings in Limassol Cyprus for university purposes, Int $\mathrm{J}$ Archit Herit 8:758-82.

Rabun, J.S. and Kelso, R. 2009. Building evaluation for adaptive reuse and preservation. Published by John Wiley \& Sons, Inc., Hoboken, New Jersey.

Remmers, 2014. Remmers IQ-Therm - The intelligent interior insulation - The unique capillary thermal insulation. http://www.remmers.co.uk/fileadmin/user_upload/brochures/interior_insulation/796__iq-therm/796_GB_iQ-Therm.pdf (accessed 2 June 2014).

Roels, S. and Carmeliet, J. 2006. Analysis of moisture flow in porous materials using microfocus X-ray radiography. Int J Heat Mass Tran 49: 4762-772.

Scheffler, G., Grunewald, J. 2003. Material development and optimisation supported by numerical simulation for a capillary-active inside insulation material. In Research in Building Physics. Edited by Carmeliet, Hens, Vermeir. Lisse: A.A. Balkema Publishers, pp. 77-85. 
Postprint: Vereecken E, Roels S. 2016. Capillary active interior insulation systems for wall retrofitting: A more nuanced story. Accepted for publication in International Journal of Architectural Heritage: Conservation, Analysis, and Restoration 10(5), p. 558-569, DOI: 10.1080/15583058.2015.1009575.

Scheffler, G. 2011. Hygric performance of internal insulation with light-weight autoclaved aerated concrete. In Proceedings $5^{\text {th }}$ International $A A C$ conference. Bydgoszcz, Poland, September 14-17, p.323-336.

Stopp, H., Strangfeld, P., Fechner, H. and Häupl, P. 2001. The hygrothermal performance of external walls with inside insulation. In Proceedings Thermal performance of the exterior envelopes of buildings VIII, Clearwater Beach, Florida.

Straube, J. and Schumacher, C. 2007. Interior insulation retrofits of load-bearing masonry walls in cold climates. Building Science Digest 114.

Vereecken, E. 2013. Hygrothermal analysis of interior insulation for renovation projects. PhD Thesis, KU Leuven, Belgium.

Vereecken, E. and Roels, S. 2014a. A comparison of the hygric performace of interior insulation systems: a hot box-cold box experiment. Energ Buildings 80:37-44.

Vereecken, E. and Roels, S. 2014b. Capillary active interior insulation: Do the advantages really offset potential disadvantages? Mater Struct, doi: 10.1617/s11527014-0373-9.

Vereecken, E., Van Gelder, L., Janssen, H. and Roels, S. 2014. Interior insulation for wall retrofitting - A probabilistic analysis of energy savings and hygrothermal risks. Energ Buildings 2015. doi.org/10.1016/j.enbuild.2014.12.031

Wang, H-J. and Zeng, Z-T. 2010. A multi-objective decision-making process for reuse selection of historic buildings, Expert Syst Appl 37:1241-49. 